\title{
Favorable Lip and Oral Cancer Mortality-To-Incidence Ratios in Countries With High Human Development Index and Expenditures On Health
}

\section{Wen-Wei Sung}

Department of Urology, Chung Shan Medical University Hospital, Taichung, Taiwan, 40201

\section{Yong-Chen Hsu}

Department of Pathology and Laboratory Medicine, Taichung Veterans General Hospital, Taichung, Taiwan, 40201

\section{Ying-Ching Chen}

School of Medicine, Chung Shan Medical University, Taichung, Taiwan, 40201

\section{Yu-Chi Chao}

School of Medicine, Chung Shan Medical University, Taichung, Taiwan, 40201

Chih-Jung Chen ( $\sim$ cjchen1016@gmail.com)

Department of Pathology and Laboratory Medicine, Taichung Veterans General Hospital, Taichung, Taiwan, 40201

\section{Research Article}

Keywords: lip and oral cancer, mortality, incidence, mortality-to-incidence ratio, expenditure, human development index

Posted Date: February 3rd, 2021

DOI: https://doi.org/10.21203/rs.3.rs-145593/v1

License: (c) (i) This work is licensed under a Creative Commons Attribution 4.0 International License. Read Full License 


\section{Abstract}

Background: The incidence rate of lip and oral cancer is increasing in recent years, the prognosis of which is associated with a country's socioeconomic status. The mortality-to-incidence ratio (MIR) is a reasonable indicator of disparities in cancer screening and treatment. We aim to understand the association between economic status and cancer prognosis.

Methods: Data were obtained from the Global Cancer Observatory (GLOBOCAN) and the World Health Organization (WHO). The MIR was applied to evaluate the correlation to healthcare expenditures and the human development index (HDI) disparities via Spearman's rank correlation coefficient.

Results: The results showed that Asia has the most cases and deaths. The association of the HDI, current health expenditure (CHE), and ratio of $\mathrm{CHE}$ to the percentage of gross domestic product (CHE/GDP) to the crude rate (CR) of incidence show significant results $(p<0.001, p=0.005$, and $p<0.001$, respectively). However, their association with the mortality rate $(p=0.303, p=0.997$, and $p=0.101)$ is not significant. In the correlation of the MIRs, the results revealed a significant association with the $\mathrm{HDI}, \mathrm{CHE}$, and $\mathrm{CHE} / \mathrm{GDP}$ with the $\mathrm{MIR}(p<0.001, p<0.001$, and $p<0.001$, respectively).

Conclusion: Countries with a higher HDI, more CHE per capita, and higher CHE/GDP tend to have a lower MIR, which indicates a favorable clinical outcome.

\section{Introduction}

Lip and oral cancer is one of the most common cancers worldwide, and the incidence rate has increased continuously in recent years [1]. South Asia and Southeast Asia has the most cases [2]. Among all anatomic subsites of lip and oral cavity cancer, the tongue is the most common affected site worldwide, and buccal/labial mucosa is the second most common affected site in Asia [3]. The most common risk factors of lip and oral cavity cancer include tobacco, alcohol, betel quid, Epstein-Barr virus and human papillomavirus infection [4, 5]. Oral cavity cancer can be diagnosed early at a lower stage with leukoplakia by visual examination, biopsy or image study; thus, early oral screening is beneficial [6]. However, poor and less educated people with risk factors seldom obtain a screening of oral cancer; thus, diagnosis is usually delayed for these people [7].

Standard treatment of oral cancer includes surgical resection, radiotherapy, chemotherapy or a combination of them, depending on their stages [8]. A previous study indicated that over the past forty years, the prognosis of oral cancer had substantially improved particularly due to the application of adjuvant therapy and adjuvant chemoradiotherapy [9]. Recently, immunotherapy has emerged as a potential and effective treatment $[8,10]$. The prognosis of oral cancer is related to several factors, such as race [11] and anatomic subsites [12]. Moreover, the early detection of oral cancer is one of the most important factors that affect the overall survival and prognosis [13], since an affordable examination target to oral cancer can help early diagnosis and improve the prognosis and survival rate [14], and the prognosis has disparities in socioeconomic status [15]. People with limited income may receive much less definitive therapy and have much more burden from oral cancer and worse overall survival rates $[16,17]$.

The mortality-to-incidence ratio (MIR), which is calculated by normalizing crude mortality rates to its incidence, which determines whether a country has a higher mortality or a lower mortality [18], reveals the overall mortality 
rate after diagnosis of the disease [19]. Previous studies, such as a study by Sunkara \& Hébert [20], suggested that the MIR could be a useful indicator to identify the regional disparities in cancer screening and treatment.

As MIR presents mortality after accounting for incidence, it can help us assess the burden and prognosis of cancer. Thus, in this study, we evaluate health expenditures, the human development index (HDI), and MIRs of different countries and aim to understand the association between economic status and cancer prognosis.

\section{Materials And Methods}

Lip and oral cavity cancer, ICD-10 C00-06, epidemiological data were obtained from the Global Cancer Observatory (GLOBOCAN) database (https://gco.iarc.fr/today/), which is a public access database that provides contemporary estimates of cancer epidemiology for 185 countries in 2018. The HDI was obtained from the United Nations Development Programme, Human Development Report Office (http://hdr.undp.org/en). The data on health expenditures, including the per capita current health expenditure $(\mathrm{CHE})$ and ratio of $\mathrm{CHE}$ to the percentage of gross domestic product (CHE/GDP), were obtained from the World Health Statistics database (https://www.who.int/gho/publications/world_health_statistics/en/).

The MIR was defined as the ratio of the crude rate (CR) of mortality to the CR of incidence, as previously described [20-23]. The exclusion criteria for country selection were based on the missing data of the World Health Organization (WHO) statistics ( $\mathrm{N}=12)$, missing data of the $\mathrm{HDI}(\mathrm{N}=2)$, and data quality report of the GLOBOCAN $(\mathrm{N}=110,[24])$. A total of 61 countries were included in the final analysis. Associations between the MIR and other factors among various countries were estimated using Spearman's rank correlation coefficient, which was calculated using SPSS statistical software version 15.0 (SPSS, Inc., Chicago, IL). The values of $p<0.05$ were considered statistically significant. Scatterplots were generated with Sigma Plot.

\section{Result}

\section{Epidemiology of lip and oral cancer according to the regions}

We survey 339,913 new cases and 168,169 deaths of lip and oral cavity cancer in this study. The rank and percentage of lip and oral cavity cancer in all cancers of selected regions and cumulative risk are shown in Table 1. The incidence rates by regions are Africa $(13,324)$, Asia $(220,810)$, Europe $(57,737)$, Latin America and the Caribbean (18,525), North America $(25,354)$, and Oceania $(4,163)$. The number of deaths by region are Africa $(9,066)$, Asia $(124,900)$, Europe $(21,834)$, Latin America and the Caribbean $(7,050)$, North America $(4,424)$, and Oceania (895). Among all selected regions, Asia has the most cases and deaths as well as the highest percentage among all cancers. Conversely, Oceania has the fewest cases and deaths.

Table 1. Summary of the number, crude rank, ASR and MIR of lip and oral cancer by region. 


\begin{tabular}{|c|c|c|c|c|c|c|c|}
\hline \multirow[b]{2}{*}{ Region } & \multicolumn{3}{|c|}{ New cases } & \multicolumn{3}{|l|}{ Deaths } & \multirow[b]{2}{*}{ MIR } \\
\hline & Number & $\mathrm{CR}$ & ASR & Number & CR & ASR & \\
\hline Africa & 13324 & 1.0 & 1.7 & 9066 & 0.7 & 1.2 & 0.71 \\
\hline Asia & 220810 & 4.9 & 4.2 & 124900 & 2.8 & 2.4 & 0.57 \\
\hline Europe & 57737 & 8.0 & 4.3 & 21834 & 3.0 & 1.6 & 0.38 \\
\hline Latin America and the Caribbean & 18525 & 2.9 & 2.6 & 7050 & 1.1 & 1.0 & 0.38 \\
\hline North America & 25354 & 7.1 & 4.2 & 4424 & 1.2 & 0.7 & 0.17 \\
\hline Oceania & 4163 & 10.2 & 7.5 & 895 & 2.2 & 1.5 & 0.22 \\
\hline
\end{tabular}

\section{Epidemiology and parameters of the development and health expenditure of lip and oral cancer of the selected countries}

The HDI, CHE, cancer incidence, cancer mortality, and MIR of selected countries are shown in Table 2. Norway has the highest HDI (0.954), and Egypt has the lowest HDI (0.700). The electronic GDP (e-GDP) ranges from $3.1 \%$ (Qatar) to $16.8 \%$ (United States of America). According to the incidence rates among all countries that were examined, Qatar and Bahrain have the lowest CR (1.0), and Chile has the lowest age standardized rate (ASR, 1.1), Latvia has the highest crude rates (12.7 of CR) and Australia has the highest ASR (6.9). Latvia has the highest mortality CR (6.0), and Egypt has the lowest mortality CR (0.4), while Latvia has the highest ASR (3.2) and Chile, Egypt, Israel, Malta and Jamaica have the lowest ASR (0.4). Australia has the lowest MIR (0.14), and Bahrain has the highest MIR (0.64).

Table 2. Summary of HDI, CHE, cancer incidence, cancer mortality, and MIR in lip and oral cancer (N=61). 


\begin{tabular}{|c|c|c|c|c|c|c|c|c|c|c|}
\hline \multirow[b]{2}{*}{ Country } & \multirow[b]{2}{*}{$\mathrm{HDI}$} & \multicolumn{2}{|l|}{ CHE } & \multicolumn{3}{|l|}{ Incidence } & \multicolumn{4}{|l|}{ Mortality } \\
\hline & & $\begin{array}{l}\text { Per } \\
\text { Capita }\end{array}$ & $\begin{array}{l}\text { \% of } \\
\text { GDP }\end{array}$ & Number & CR & ASR & Number & $\mathrm{CR}$ & ASR & MIR \\
\hline Argentina & 0.830 & 998 & 6.8 & 1357 & 3.1 & 2.5 & 512 & 1.2 & 0.9 & 0.39 \\
\hline Australia & 0.938 & 4934 & 9.4 & 2682 & 11.1 & 6.9 & 378 & 1.6 & 0.9 & 0.14 \\
\hline Austria & 0.914 & 4536 & 10.3 & 488 & 5.7 & 3.0 & 232 & 2.7 & 1.4 & 0.47 \\
\hline Bahrain & 0.838 & 1190 & 5.2 & 16 & 1.0 & 1.5 & 10 & 0.6 & 1.0 & 0.64 \\
\hline Belarus & 0.817 & 352 & 6.1 & 653 & 7.0 & 4.1 & 316 & 3.4 & 2.0 & 0.49 \\
\hline Belgium & 0.919 & 4228 & 10.5 & 923 & 8.3 & 4.7 & 305 & 2.7 & 1.4 & 0.33 \\
\hline Brazil & 0.761 & 780 & 8.9 & 9902 & 4.7 & 4.0 & 3965 & 1.9 & 1.6 & 0.40 \\
\hline Bulgaria & 0.816 & 572 & 8.2 & 459 & 6.7 & 3.4 & 164 & 2.4 & 1.2 & 0.36 \\
\hline Canada & 0.922 & 4508 & 10.4 & 2633 & 7.3 & 3.9 & 594 & 1.6 & 0.8 & 0.22 \\
\hline Chile & 0.847 & 1102 & 8.1 & 275 & 1.5 & 1.1 & 113 & 0.6 & 0.4 & 0.42 \\
\hline Colombia & 0.761 & 374 & 6.2 & 775 & 1.6 & 1.4 & 308 & 0.6 & 0.5 & 0.39 \\
\hline Costa Rica & 0.794 & 929 & 8.1 & 78 & 1.6 & 1.2 & 35 & 0.7 & 0.5 & 0.44 \\
\hline Croatia & 0.837 & 852 & 7.4 & 291 & 7.2 & 3.8 & 117 & 2.9 & 1.5 & 0.40 \\
\hline Cuba & 0.778 & 826 & 10.9 & 1238 & 11.0 & 6.2 & 380 & 3.4 & 1.8 & 0.31 \\
\hline Cyprus & 0.873 & 1563 & 6.8 & 29 & 2.5 & 1.6 & 8 & 0.7 & 0.5 & 0.27 \\
\hline Czechia & 0.891 & 1284 & 7.3 & 859 & 8.3 & 4.3 & 361 & 3.5 & 1.8 & 0.42 \\
\hline Denmark & 0.930 & 5497 & 10.3 & 397 & 7.1 & 3.8 & 125 & 2.2 & 1.1 & 0.31 \\
\hline Ecuador & 0.758 & 530 & 8.5 & 217 & 1.3 & 1.2 & 82 & 0.5 & 0.5 & 0.38 \\
\hline Egypt & 0.700 & 157 & 4.2 & 1295 & 1.3 & 1.6 & 352 & 0.4 & 0.4 & 0.28 \\
\hline Estonia & 0.882 & 1112 & 6.5 & 79 & 6.2 & 3.3 & 40 & 3.1 & 1.7 & 0.50 \\
\hline Fiji & 0.724 & 175 & 3.6 & 27 & 3.0 & 2.9 & 11 & 1.2 & 1.2 & 0.40 \\
\hline Finland & 0.925 & 4005 & 9.4 & 348 & 6.5 & 3.0 & 116 & 2.2 & 0.9 & 0.34 \\
\hline France & 0.891 & 4026 & 11.1 & 6815 & 10.8 & 6.2 & 1516 & 2.4 & 1.3 & 0.22 \\
\hline Germany & 0.939 & 4592 & 11.2 & 7271 & 9.1 & 4.4 & 2311 & 2.9 & 1.3 & 0.32 \\
\hline Iceland & 0.938 & 4375 & 8.6 & 13 & 3.9 & 2.3 & 3 & 0.9 & 0.5 & 0.23 \\
\hline Ireland & 0.942 & 4757 & 7.8 & 275 & 5.8 & 3.7 & 74 & 1.6 & 0.9 & 0.28 \\
\hline Israel & 0.906 & 2756 & 7.4 & 155 & 1.9 & 1.4 & 51 & 0.6 & 0.4 & 0.32 \\
\hline Italy & 0.883 & 2700 & 9.0 & 3500 & 6.1 & 2.7 & 1184 & 2.1 & 0.9 & 0.34 \\
\hline Jamaica & 0.726 & 294 & 5.9 & 52 & 1.8 & 1.5 & 15 & 0.5 & 0.4 & 0.29 \\
\hline
\end{tabular}




\begin{tabular}{|c|c|c|c|c|c|c|c|c|c|c|}
\hline Japan & 0.915 & 3733 & 10.9 & 8138 & 6.7 & 2.8 & 2496 & 2.1 & 0.7 & 0.31 \\
\hline Kuwait & 0.808 & 1169 & 4.0 & 59 & 1.4 & 2.0 & 33 & 0.8 & 1.1 & 0.56 \\
\hline Latvia & 0.854 & 784 & 5.8 & 239 & 12.7 & 6.8 & 113 & 6.0 & 3.2 & 0.47 \\
\hline Lithuania & 0.869 & 923 & 6.5 & 188 & 6.7 & 3.7 & 114 & 4.1 & 2.3 & 0.61 \\
\hline Luxembourg & 0.909 & 6236 & 6.0 & 45 & 7.8 & 4.8 & 10 & 1.7 & 1.0 & 0.22 \\
\hline Malaysia & 0.804 & 386 & 4.0 & 640 & 2.0 & 2.0 & 302 & 1.0 & 1.0 & 0.48 \\
\hline Malta & 0.885 & 2304 & 9.6 & 18 & 4.2 & 1.9 & 6 & 1.4 & 0.4 & 0.33 \\
\hline Mauritius & 0.796 & 506 & 5.5 & 62 & 4.9 & 3.3 & 28 & 2.2 & 1.5 & 0.45 \\
\hline Netherlands & 0.934 & 4746 & 10.7 & 1418 & 8.5 & 4.4 & 257 & 1.5 & 0.7 & 0.18 \\
\hline New Zealand & 0.921 & 3554 & 9.3 & 264 & 5.7 & 3.4 & 58 & 1.2 & 0.7 & 0.21 \\
\hline Norway & 0.954 & 7464 & 10.0 & 362 & 6.9 & 3.7 & 68 & 1.3 & 0.7 & 0.19 \\
\hline Oman & 0.834 & 636 & 3.8 & 65 & 1.3 & 2.0 & 31 & 0.6 & 1.1 & 0.49 \\
\hline Philippines & 0.712 & 127 & 4.4 & 1372 & 1.3 & 1.6 & 673 & 0.6 & 0.8 & 0.48 \\
\hline Poland & 0.872 & 797 & 6.3 & 3203 & 8.6 & 4.8 & 1505 & 4.0 & 2.2 & 0.47 \\
\hline Portugal & 0.850 & 1722 & 9.0 & 817 & 8.2 & 4.3 & 269 & 2.7 & 1.4 & 0.33 \\
\hline Qatar & 0.848 & 2030 & 3.1 & 26 & 1.0 & 2.0 & 14 & 0.5 & 1.4 & 0.54 \\
\hline $\begin{array}{l}\text { Russian } \\
\text { Federation }\end{array}$ & 0.824 & 524 & 5.6 & 9340 & 6.6 & 4.0 & 5443 & 3.8 & 2.3 & 0.58 \\
\hline Serbia & 0.799 & 491 & 9.4 & 701 & 8.1 & 4.9 & 261 & 3.0 & 1.7 & 0.37 \\
\hline Singapore & 0.935 & 2280 & 4.3 & 199 & 3.5 & 1.9 & 85 & 1.5 & 0.8 & 0.43 \\
\hline Slovakia & 0.857 & 1108 & 6.9 & 541 & 10.1 & 6.0 & 224 & 4.2 & 2.5 & 0.42 \\
\hline Slovenia & 0.902 & 1772 & 8.5 & 135 & 6.7 & 3.5 & 47 & 2.3 & 1.1 & 0.34 \\
\hline South Africa & 0.705 & 471 & 8.2 & 1328 & 2.3 & 2.7 & 829 & 1.4 & 1.7 & 0.61 \\
\hline South Korea & 0.906 & 2013 & 7.4 & 1467 & 2.9 & 1.6 & 507 & 1.0 & 0.5 & 0.34 \\
\hline Spain & 0.893 & 2354 & 9.2 & 3843 & 8.6 & 4.0 & 969 & 2.2 & 1.0 & 0.26 \\
\hline Sweden & 0.937 & 5600 & 11.0 & 556 & 5.7 & 2.8 & 145 & 1.5 & 0.7 & 0.26 \\
\hline Switzerland & 0.946 & 9818 & 12.1 & 639 & 7.7 & 4.0 & 184 & 2.2 & 1.1 & 0.29 \\
\hline Thailand & 0.765 & 217 & 3.8 & 4169 & 6.1 & 3.8 & 2159 & 3.2 & 2.0 & 0.52 \\
\hline $\begin{array}{l}\text { Trinidad and } \\
\text { Tobago }\end{array}$ & 0.799 & 1146 & 6.0 & 42 & 3.1 & 2.2 & 20 & 1.5 & 1.1 & 0.48 \\
\hline Ukraine & 0.750 & 125 & 6.1 & 3358 & 7.8 & 4.4 & 2058 & 4.7 & 2.8 & 0.60 \\
\hline $\begin{array}{l}\text { United } \\
\text { Kingdom }\end{array}$ & 0.920 & 4356 & 9.9 & 5645 & 8.7 & 4.9 & 1443 & 2.2 & 1.1 & 0.25 \\
\hline United States of & 0.920 & 9536 & 16.8 & 22715 & 7.1 & 4.2 & 3830 & 1.2 & 0.7 & 0.17 \\
\hline
\end{tabular}




\section{Association between MIR and parameters of the development and health expenditure of the selected countries}

We further examined the association between the HDI, CHE and CRs of incidence and mortality (Fig 1). The association between $\mathrm{HDI}$ and $\mathrm{CR}$ of incidence $(p<0.001$, Figs $1 \mathrm{~A})$ yields significant results, while mortality $(p=0.303$, Figs 1B) does not yield significant results. On the other hand, the incidence of CHE to CR and CHE/GDP to CR show significant results ( $p=0.005$, Figs $1 C ; p<0.001$, Figs $1 \mathrm{E}$, respectively), while the mortality of the $\mathrm{CHE}$ to the $\mathrm{CR}$ and the $\mathrm{CHE} / \mathrm{GDP}$ to the CR do not yield significant results ( $p=0.997$, Figs 1D; $p=0.101$, Figs $1 \mathrm{~F}$, respectively). In the correlation of MIRs, the results revealed a significant association for the HDI, CHE per capita, USD, and CHE/GDP with the MIR in lip and oral cancer (coefficient correlation: $-0.597, p<0.001$; coefficient correlation: $-0.652, p<0.001$; coefficient correlation: $-0.651, p<0.001$ respectively, Fig 2).

\section{Discussion}

In our study, we analyzed and compared the incidence, mortality, HDI and CHE of selected countries. Asia has the most cases and deaths among all regions; these results showed the correlation between the geographic distribution of betel chewing and high oral cancer incidence and mortality. In Asia, especially Southeast Asia, betel quid chewing with different ingredients is a prevalent oral habit [5]. Betel quid has been considered a carcinogen by the International Agency for Research on Cancer (IARC) for years [25]. Previous results showed that betel quid chewing has a significant impact on oral cancer and precancer [26]. A longer duration and greater daily amount of betel quid chewing will also increase the risk of oral cancer [27].

We determined that countries with higher HDIs and CHEs have higher incidence rates (Fig 1). This result supports the findings of a previous study that indicates that cancer incidence burden is greater in countries with higher HDIs [28]. These findings may be due to the tendency of more developed countries to have relatively comprehensive medical facilities, cancer screening systems and patient education.

Some novel methods, such as Toluidine blue staining, brush biopsy, chemiluminescence and tissue fluorescence spectroscopy, aid early diagnosis in the screening of oral cancer [29]. Early detection of oral cancer and public awareness about oral cancer screenings could reduce mortality rates and contribute to better outcomes [30]. Previous results also showed that socioeconomic disparities influence the frequency of oral cancer screening and screening methods [7], which affect the severity at diagnosis and prognosis [31].

However, when corrected incidence and mortality results with MIR, we discovered that more developed countries have lower MIRs (Fig 2), which indicates longer survival rates. A retrospective study showed that advanced preoperative image assessment, efficient radiotherapy and improved operative techniques enabled a substantial increase in the survival rate in recent decades [32]. In addition to operative resection, chemotherapy and radiation therapy, new options such as immunotherapy and target therapy have become increasingly popular in treating oral cancer, especially in advanced stages [8]. Due to the deeper understanding of oncogenic and epigenetic pathways of oral cancer, more biomarkers for identifying invasive and metastatic potential tumors are discovered, and precision therapy based on genetic findings is improving [33]. Thus, countries with higher HDIs and CHEs may facilitate early detection, in combination with effective treatment, and cause higher incidence rates but lower MIRs, which is compatible with our results. 
A previous paper showed that the MIR falls short of comprehensive follow up, which would not be able to replace cancer survival rates or prognostic data from long-term follow up or a cohort study [34]. However, other studies showed that the MIR is a simple and efficient method for identifying cancer control [35]. The MIR is also shown to be a suitable method for examining cancer screening and treatment programs worldwide [20].

\section{Limitations}

Our results still have some limitations. First, some important risk factors of lip and oral cancer, such as alcohol consumption, smoking, betel chewing, and other oral behaviors among different countries, were not recorded and fully analyzed. These risk factors may have important roles in explaining and determining the incidence and mortality rates among countries and regions. Second, the feasibility of using WHO rankings and e-GDP to represent the healthcare disparities of countries has not been confirmed to specifically apply to different cancers. Other factors, such as national health care systems, disparity in access to cancer care, and insurance coverage, should also be analyzed. Despite these limitations, the MIR appears to provide more accessible data when compared with long-term follow up survival surveys.

\section{Conclusions}

The MIR for lip and oral cancer is significantly associated with the HDI, CHE per capita, and CHE/GDP. Countries with higher HDIs, higher CHE per capita, and higher CHE/GDP tend to have longer survival rates.

\section{Abbreviations}

MIR: mortality-to-incidence ratio; WHO: the World Health Organization; HDI: human development index; $\mathrm{CHE}$ : current health expenditure; GDP: gross domestic product; CR: crude rate; ASR: age standardized rate.

\section{Declarations}

Ethics approval and consent to participate: Not Applicable.

Consent for publication: Not Applicable.

Availability of data and materials: The datasets used and/or analyzed during the current study are publicly available in Global Cancer Observatory (GLOBOCAN) database (https://gco.iarc.fr/today/), United Nations Development Programme/Human Development Report Office (http://hdr.undp.org/en) and World Health Statistics database (https://www.who.int/gho/publications/world_health_statistics/en/).

Competing interests: The authors declare that they have no competing interests.

Funding: There was no funding or grant supports this study.

Authors' contributions: Conceptualization (Chih-Jung Chen), Data Analysis (Wen-Wei Sung and Yong-Chen Hsu), Methodology (Yong-Chen Hsu and Ying-Ching Chen), Supervision (Chih-Jung Chen and Wen-Wei Sung), Validation (Yong-Chen Hsu and Yu-Chi Chao), Writing-original draft, review and editing (Ying-Ching Chen, Yu-Chi Chao and Wen-Wei Sung). All authors read and approved the final version of the manuscript.

Corresponding author: Correspondence to Chih-Jung Chen. 
Acknowledgements: Not Applicable.

Lip and oral cavity cancer, ICD-10 C00-06, epidemiological data were obtained from the Global Cancer Observatory (GLOBOCAN) database (https://gco.iarc.fr/today/), which is a public access database that provides contemporary estimates of cancer epidemiology for 185 countries in 2018. The HDI was obtained from the United Nations Development Programme, Human Development Report Office (http://hdr.undp.org/en). The data on health expenditures, including the per capita current health expenditure (CHE) and ratio of $\mathrm{CHE}$ to the percentage of gross domestic product (CHE/GDP), were obtained from the World Health Statistics database (https://www.who.int/gho/publications/world_health_statistics/en/).

\section{References}

1. Siegel RL, Miller KD, Jemal A. Cancer statistics, 2020. 2020;70(1):7-30.

2. Ghantous Y, Abu Elnaaj I. [GLOBAL INCIDENCE AND RISK FACTORS OF ORAL CANCER]. Harefuah. 2017;156(10):645-9.

3. Dhanuthai K, Rojanawatsirivej S, Thosaporn W, Kintarak S, Subarnbhesaj A, Darling M, et al. Oral cancer: A multicenter study. Medicina oral, patologia oral y cirugia bucal. 2018;23(1):e23-e9.

4. LeHew CW, Weatherspoon DJ, Peterson CE, Goben A, Reitmajer K, Sroussi H, et al. The Health System and Policy Implications of Changing Epidemiology for Oral Cavity and Oropharyngeal Cancers in the United States From 1995 to 2016. Epidemiologic reviews. 2017;39(1):132-47.

5. Kumar M, Nanavati R, Modi TG, Dobariya C. Oral cancer: Etiology and risk factors: A review. Journal of cancer research and therapeutics. 2016;12(2):458-63.

6. Yanik EL, Katki HA, Silverberg MJ, Manos MM, Engels EA, Chaturvedi AK. Leukoplakia, Oral Cavity Cancer Risk, and Cancer Survival in the U.S. Elderly. Cancer prevention research (Philadelphia, Pa). 2015;8(9):857-63.

7. Kravietz A, Angara P, Le M, Sargi Z. Disparities in Screening for Head and Neck Cancer: Evidence from the NHANES, 2011-2014. Otolaryngology-head and neck surgery : official journal of American Academy of Otolaryngology-Head and Neck Surgery. 2018;159(4):683-91.

8. Kaidar-Person O, Gil Z, Billan S. Precision medicine in head and neck cancer. Drug resistance updates : reviews and commentaries in antimicrobial and anticancer chemotherapy. 2018;40:13-6.

9. Cheraghlou S, Schettino A, Zogg CK, Judson BL. Changing prognosis of oral cancer: An analysis of survival and treatment between 1973 and 2014. The Laryngoscope. 2018;128(12):2762-9.

10. D'Cruz AK, Vaish R, Dhar H. Oral cancers: Current status. Oral oncology. 2018;87:64-9.

11. Yu AJ, Choi JS, Swanson MS, Kokot NC, Brown TN, Yan G, et al. Association of Race/Ethnicity, Stage, and Survival in Oral Cavity Squamous Cell Carcinoma: A SEER Study. OTO open. 2019;3(4):2473974x19891126.

12. Farhood Z, Simpson M, Ward GM, Walker RJ, Osazuwa-Peters N. Does anatomic subsite influence oral cavity cancer mortality? A SEER database analysis. The Laryngoscope. 2019;129(6):1400-6.

13. Ghantous Y, Yaffi V, Abu-Elnaaj I. [Oral cavity cancer: epidemiology and early diagnosis]. Refu'at ha-peh vehashinayim (1993). 2015;32(3):55-63, 71.

14. Akinkugbe AA, Garcia DT, Brickhouse TH, Mosavel M. Lifestyle risk factor related disparities in oral cancer examination in the U.S: a population-based cross-sectional study. BMC public health. 2020;20(1):153.

15. Gaubatz ME, Bukatko AR, Simpson MC, Polednik KM, Adjei Boakye E, Varvares MA, et al. Racial and socioeconomic disparities associated with 90-day mortality among patients with head and neck cancer in the 
United States. Oral oncology. 2019;89:95-101.

16. Agarwal P, Agrawal RR, Jones EA, Devaiah AK. Social determinants of health and oral cavity cancer treatment and survival: A competing risk analysis. The Laryngoscope. 2019.

17. Inverso G, Mahal BA, Aizer AA, Donoff RB, Chuang SK. Health Insurance Affects Head and Neck Cancer Treatment Patterns and Outcomes. Journal of oral and maxillofacial surgery : official journal of the American Association of Oral and Maxillofacial Surgeons. 2016;74(6):1241-7.

18. Choi E, Lee S, Nhung BC, Suh M, Park B, Jun JK, et al. Cancer mortality-to-incidence ratio as an indicator of cancer management outcomes in Organization for Economic Cooperation and Development countries. Epidemiol Health. 2017;39:e2017006.

19. Eberth JM, Zahnd WE, Adams SA, Friedman DB, Wheeler SB, Hebert JR. Mortality-to-incidence ratios by US Congressional District: Implications for epidemiologic, dissemination and implementation research, and public health policy. Preventive medicine. 2019;129s:105849.

20. Sunkara V, Hebert JR. The colorectal cancer mortality-to-incidence ratio as an indicator of global cancer screening and care. Cancer. 2015;121(10):1563-9.

21. Chen SL, Wang SC, Ho CJ, Kao YL, Hsieh TY, Chen WJ, et al. Prostate Cancer Mortality-To-Incidence Ratios Are Associated with Cancer Care Disparities in 35 Countries. Sci Rep. 2017;7:40003.

22. Sung WW, Wang SC, Hsieh TY, Ho CJ, Huang CY, Kao YL, et al. Favorable mortality-to-incidence ratios of kidney Cancer are associated with advanced health care systems. BMC Cancer. 2018;18(1):792.

23. Wang SC, Sung WW, Kao YL, Hsieh TY, Chen WJ, Chen SL, et al. The gender difference and mortality-toincidence ratio relate to health care disparities in bladder cancer: National estimates from 33 countries. Sci Rep. 2017;7(1):4360.

24. Huang CY, Au KK, Chen SL, Wang SC, Liao CY, Hsu HH, et al. Unfavorable Mortality-To-Incidence Ratio of Lung Cancer Is Associated with Health Care Disparity. Int J Environ Res Public Health. 2018;15(12).

25. Personal habits and indoor combustions. Volume $100 \mathrm{E}$. A review of human carcinogens. IARC monographs on the evaluation of carcinogenic risks to humans. 2012;100(Pt E):1-538.

26. Song H, Wan Y, Xu YY. Betel quid chewing without tobacco: a meta-analysis of carcinogenic and precarcinogenic effects. Asia-Pacific journal of public health. 2015;27(2):Np47-57.

27. Guha N, Warnakulasuriya S, Vlaanderen J, Straif K. Betel quid chewing and the risk of oral and oropharyngeal cancers: a meta-analysis with implications for cancer control. International journal of cancer. 2014;135(6):1433-43.

28. Fidler MM, Bray F, Soerjomataram I. The global cancer burden and human development: A review. Scandinavian journal of public health. 2018;46(1):27-36.

29. Jitender S, Sarika G, Varada HR, Omprakash Y, Mohsin K. Screening for oral cancer. Journal of experimental therapeutics \& oncology. 2016;11(4):303-7.

30. Tax CL, Haslam SK, Brillant M, Doucette HJ, Cameron JE, Wade SE. Oral cancer screening: knowledge is not enough. International journal of dental hygiene. 2017;15(3):179-86.

31. Molina MA, Cheung MC, Perez EA, Byrne MM, Franceschi D, Moffat FL, et al. African American and poor patients have a dramatically worse prognosis for head and neck cancer: an examination of 20,915 patients. Cancer. 2008;113(10):2797-806.

32. Amit M, Yen T-C, Liao C-T, Chaturvedi P, Agarwal JP, Kowalski LP, et al. Improvement in survival of patients with oral cavity squamous cell carcinoma: An international collaborative study. 2013;119(24):4242-8. 
33. Li CC, Shen Z, Bavarian R, Yang F, Bhattacharya A. Oral Cancer: Genetics and the Role of Precision Medicine. Dental clinics of North America. 2018;62(1):29-46.

34. Ellis L, Belot A, Rachet B, Coleman MP. The Mortality-to-Incidence Ratio Is Not a Valid Proxy for Cancer Survival. J Glob Oncol. 2019;5:1-9.

35. Asadzadeh Vostakolaei F, Karim-Kos HE, Janssen-Heijnen ML, Visser O, Verbeek AL, Kiemeney LA. The validity of the mortality to incidence ratio as a proxy for site-specific cancer survival. European journal of public health. 2011;21(5):573-7.

\section{Figures}

(A)

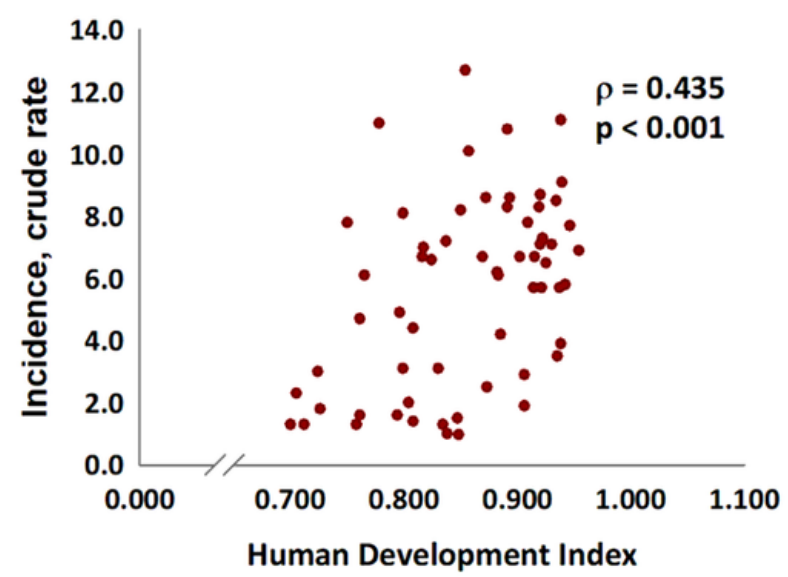

(C)

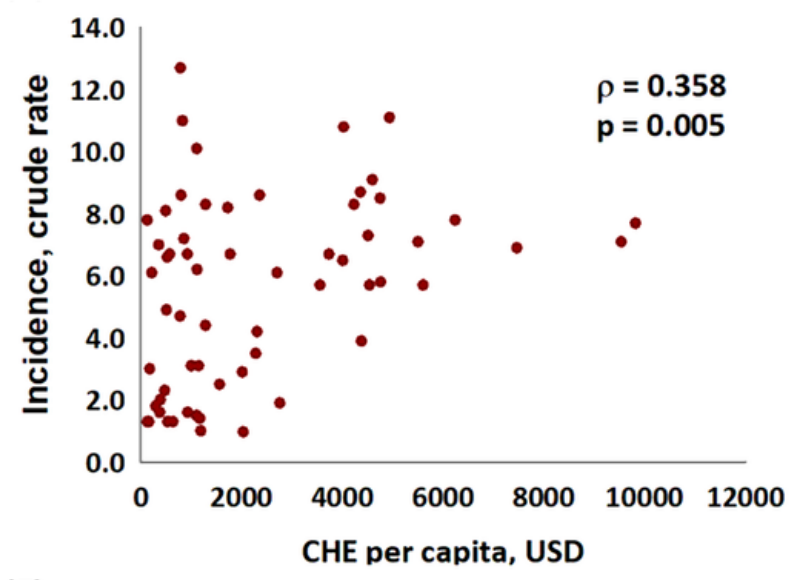

(E)

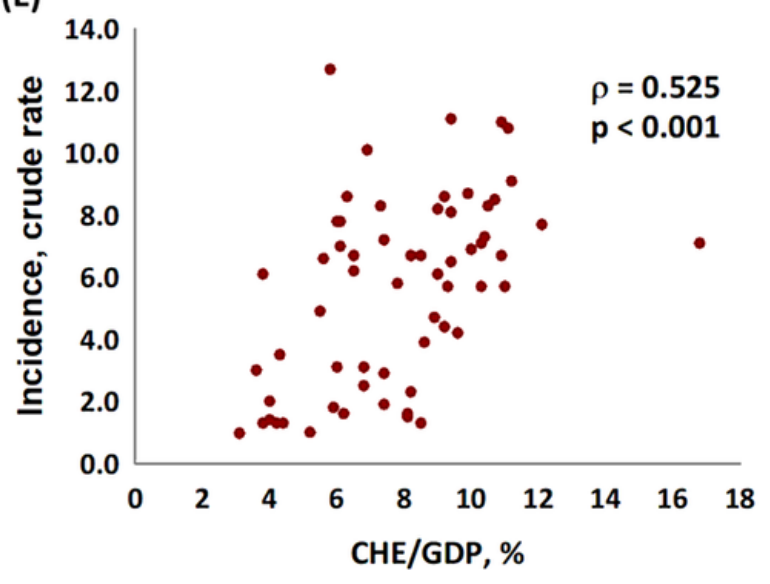

(B)

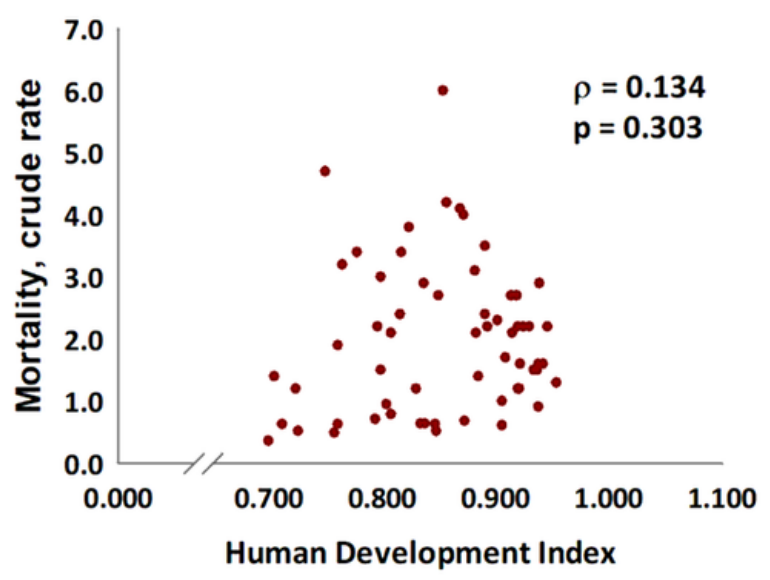

(D)

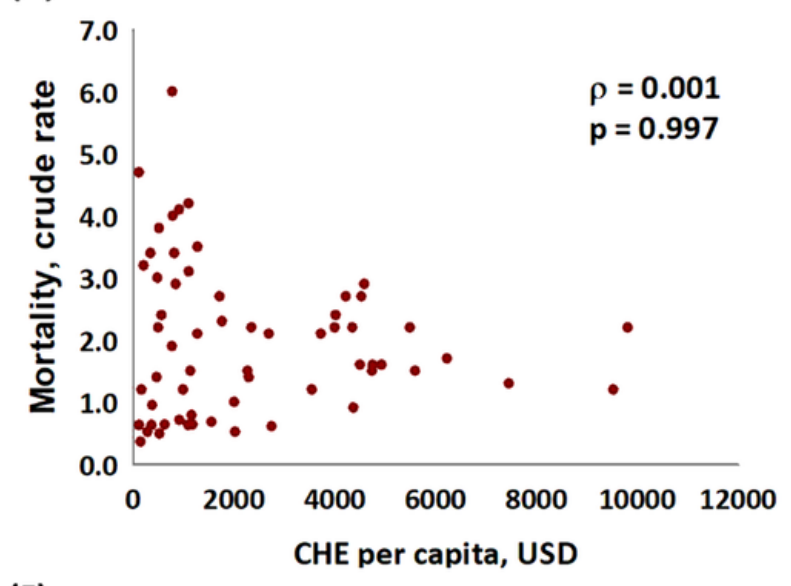

(F)

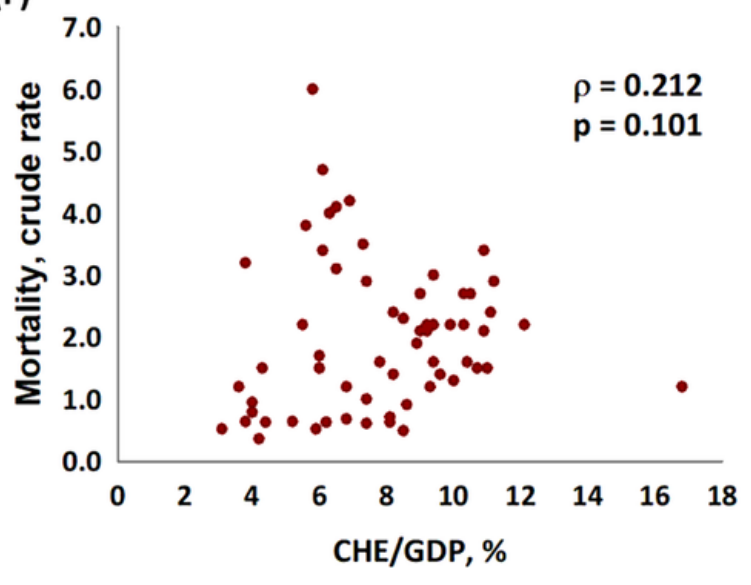


Figure 1

Association between HDI, CHE and CRs of ( $A, C$, and $E)$ incidence, and (B, D, and F) mortality in lip and oral cancer.
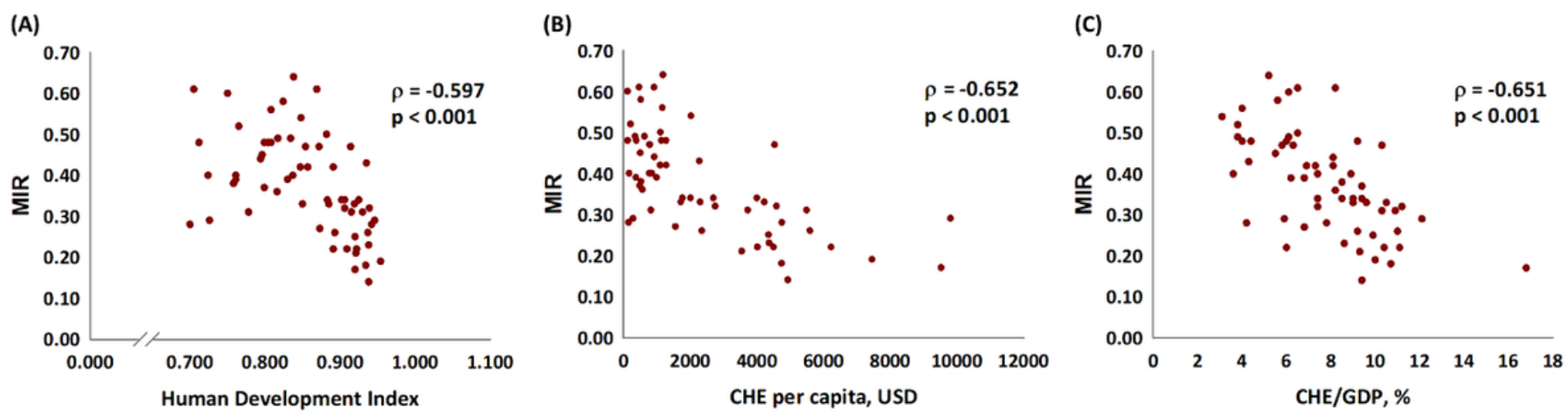

\section{Figure 2}

(A) HDI, (B) CHE per capita, and (C) CHE/GDP are significantly associated with the MIR for lip and oral cancer. 